\title{
ELECTRONICALLY TUNABLE QUADRATURE OSCILLATOR USING TRANSLINEAR CONVEYORS AND GROUNDED CAPACITORS
}

\author{
SUDHANSHU MAHESHWARI* \\ Department of Electronics Engineering, Z.H. College of Engineering \\ and Technology, Aligarh Muslim University, Aligarh - 202 002, India
}

(Received 28 December 2002; In final form 21 March 2003)

\begin{abstract}
A new electronically tunable current-mode sinusoidal oscillator with three quadrature outputs is presented. The proposed circuit employs three translinear conveyors and two grounded capacitors to realize three quadrature outputs with independent frequency control. The circuit requires no resistors and the frequency of the oscillator can be varied over a wide range by external current control. RSPICE simulation results using the bipolar implementation of translinear conveyors are given to support the proposed circuit.
\end{abstract}

Keywords: Translinear-C oscillators; Current-controlled conveyors

\section{INTRODUCTION}

Translinear conveyors or current-controlled conveyors (CCCIIs) have gained popularity for realizing current-mode circuit as these devices provide high frequency operation, electronic adjustability and the possibility of resistorless realizations [1-3]. Translinear conveyors offer current-controllable resistance at one of the ports, thus eliminating the use of external resistors for realizing electronic functions [4]. A few sinusoidal oscillators based on this technique are also available in technical literature $[3,5]$. In this paper, a new sinusoidal oscillator using three CCCIIs and two grounded capacitors suited for IC implementation is proposed. The new current-mode circuit realizes three quadrature outputs. The frequency of oscillator is electronically controllable and independent of the condition of oscillation. The proposed translinear-C oscillator possesses low THD, and is verified by RSPICE simulations.

\footnotetext{
* E-mail: maheshwarispm@ rediffmail.com
} 


\section{PROPOSED CIRCUIT}

The proposed translinear-C sinusoidal oscillator circuit is shown in Figure 1(a). Routine analysis of the circuit keeping in view the port relationships of CCCII yields the following characteristic equation $[1,2]$ :

$$
s^{2}+s \frac{R_{x 3}-R_{x 2}}{R_{x 2} R_{x 3} C_{1}}+\frac{1}{R_{x 1} R_{x 2} C_{1} C_{2}}=0 .
$$

It is clear from Eq. (1) that the frequency of oscillation (FO) and the condition of oscillation (CO) are as follows:

$$
\text { FO: } \omega_{0}=\frac{1}{\mathrm{R}_{\mathrm{x} 1} \mathrm{R}_{\mathrm{x} 2} \mathrm{C}_{1} \mathrm{C}_{2}}, \quad \text { CO: } \mathrm{R}_{\mathrm{x} 3} \leq \mathrm{R}_{\mathrm{x} 2} \text {. }
$$

Here, $R_{x i}=V_{T} / 2 I_{o i}, i=1,2,3$ is the intrinsic resistance at the terminal $X$ of the ith translinear conveyor, $V_{T}$ is the thermal voltage and $I_{o i}$ is the bias current of the ith conveyor $[1,6]$. It is to
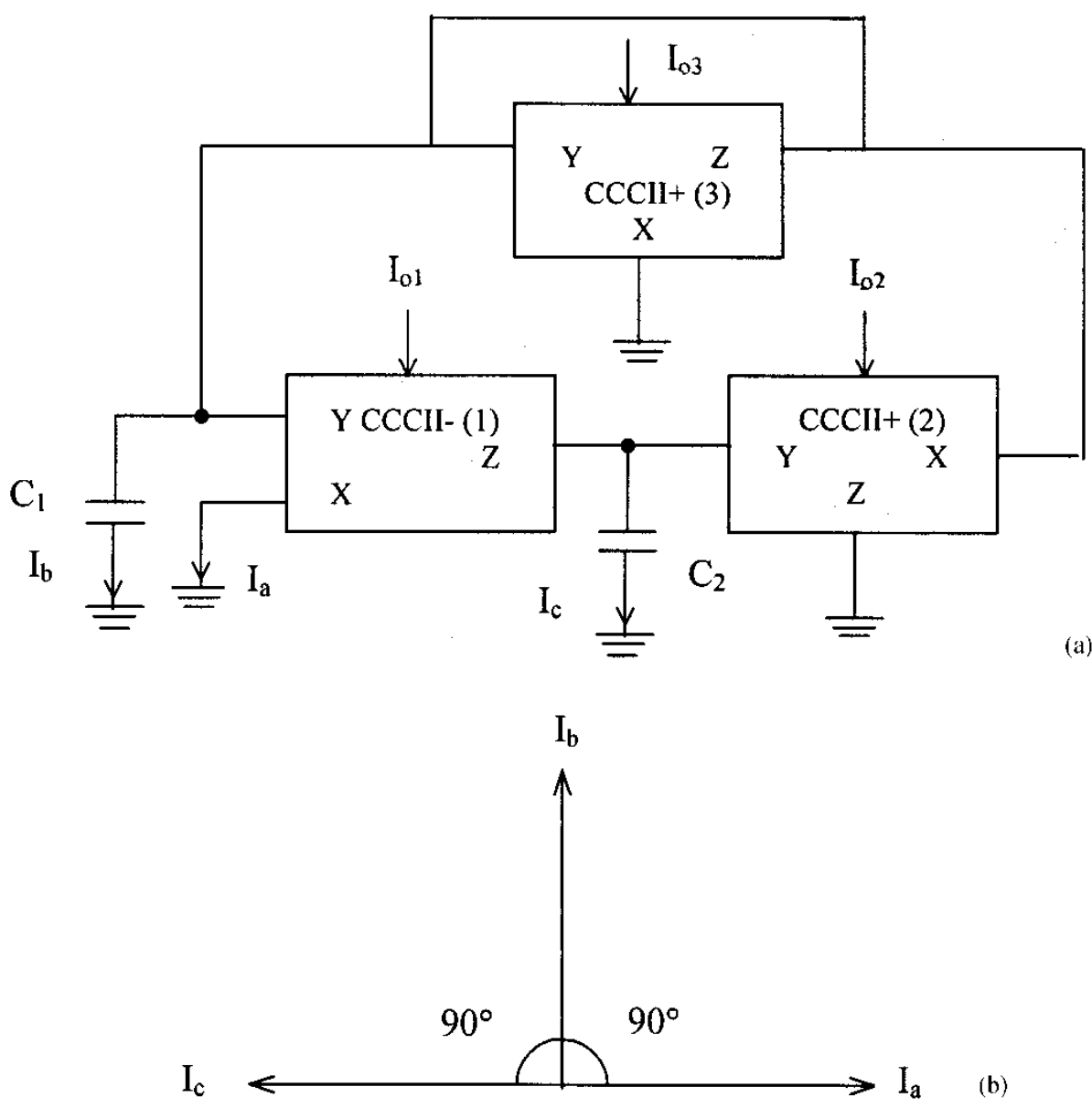

FIGURE 1 (a) Proposed translinear-C oscillator; (b) Phasor diagram. 
be noted that translinear conveyors 2 and 3 are $\mathrm{CCCII+} \mathrm{(plus} \mathrm{type)} \mathrm{whereas} \mathrm{translinear} \mathrm{con-}$ veyor 1 is $\mathrm{CCCII-} \mathrm{(minus} \mathrm{type).} \mathrm{It} \mathrm{is} \mathrm{evident} \mathrm{from} \mathrm{Eq.} \mathrm{(2)} \mathrm{that} \mathrm{the} \mathrm{FO} \mathrm{is} \mathrm{independent} \mathrm{of} \mathrm{the}$ $\mathrm{CO}$ i.e. the $\mathrm{FO}$ can be electronically controlled independently of the $\mathrm{CO}$ by varying $\mathrm{I}_{01}\left(\mathrm{R}_{\mathrm{x} 1}\right)$. Similarly the $\mathrm{CO}$ can be maintained independently of the $\mathrm{FO}$ by controlling $\mathrm{I}_{03}\left(\mathrm{R}_{\mathrm{x} 3}\right)$. At oscillating frequency with $s=j \omega$

$$
\mathrm{I}_{\mathrm{a}}=-j \mathrm{k} \mathrm{b}_{\mathrm{b}}, \quad \mathrm{I}_{\mathrm{c}}=j \mathrm{j} \mathrm{l}_{\mathrm{b}} ; \quad \text { where } \mathrm{k}=\frac{1}{\mathrm{R}_{\mathrm{x} 1} \mathrm{C}_{1}} .
$$

Equation (3) depicts the three quadrature outputs as shown in Figure 1(b).

\section{SIMULATION RESULTS}

The proposed translinear-C oscillator is verified using RSPICE simulations. Bipolar implementation of $\mathrm{CCCII}$ is used in simulation with model parameters of transistors NR100N and PR100N with a supply voltage $\pm 2.5 \mathrm{~V}[3,7]$. The circuit of Figure $1(\mathrm{a})$ was designed for the oscillating frequency of $12 \mathrm{kHz}$. The designed values were as $\mathrm{C}_{1}=\mathrm{C}_{2}=100 \mathrm{nF}, \mathrm{I}_{01}=\mathrm{I}_{02}=100 \mu \mathrm{A}$. The condition of oscillation was set by bias current $\mathrm{I}_{03}$ and sustained oscillations were obtained for a value of $\mathrm{I}_{03}=106 \mu \mathrm{A}$. The transient response of the circuit is shown in Figure 2 and confirms the validity of the circuit. The outputs show a THD of less than $1 \%$ that represents a low value. Next the electronic tuning aspect of the circuit is verified. The frequency of oscillation is varied with the bias current $\mathrm{I}_{01}$ for $\mathrm{C}_{1}=\mathrm{C}_{2}=10 \mathrm{nF}$ and $\mathrm{I}_{02}=100 \mu \mathrm{A}$. The condition of oscillation is maintained by controlling $\mathrm{I}_{03}$. The electronic tuning of the oscillator is shown in Figure 3 that gives a variation of $\mathrm{FO}$ from $37 \mathrm{kHz}$ to $375 \mathrm{kHz}$ with $\mathrm{I}_{01}$ in the range $10 \mu \mathrm{A}$ to $1000 \mu \mathrm{A}$, respectively.

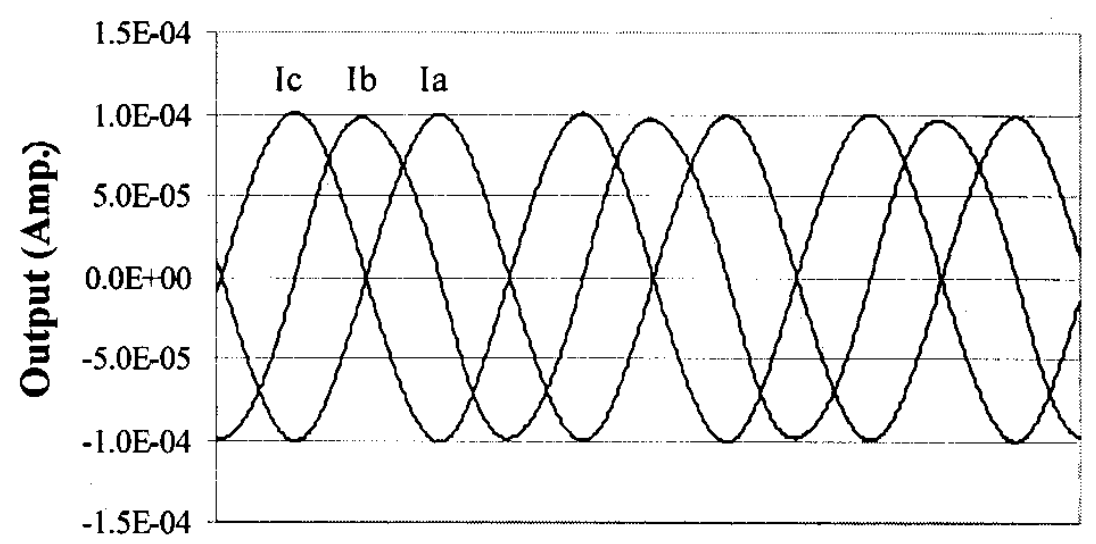

$5.000 \mathrm{E}-04, \quad 5.500 \mathrm{E}-04, \quad 6.000 \mathrm{E}-04, \quad 6.500 \mathrm{E}-04, \quad 7.000 \mathrm{E}-04, \quad 7.500 \mathrm{E}-04$,

Time (s)

FIGURE 2 Simulation results for the proposed circuit. 


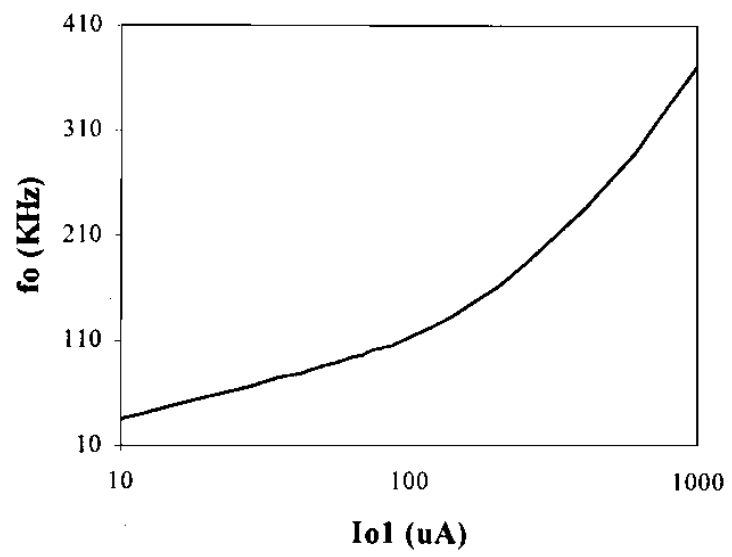

FIGURE 3 Electronic frequency tuning for $\mathrm{C}_{1}=\mathrm{C}_{2}=10 \mathrm{nF}$.

\section{CONCLUSION}

A new current-mode sinusoidal oscillator with three quadrature outputs, employing only translinear conveyors and grounded capacitors is presented. The circuit requires no external resistors, provides non-interactive electronic control of oscillating frequency over a wide range by external current and is suited for IC implementation. RSPICE simulation results confirm the validity of the proposed circuit.

\section{References}

[1] Fabre, A., Saaid, O., Wiest, F. and B oucheron, C. (1995). Current controlled bandpass filter based on translinear conveyors. Electronics Letters, 31, 1727-1728.

[2] Fabre, A., Saaid, O., Wiest, F. and Boucheron, C. (1996). High frequency applications based on a new current controlled conveyor. IEEE Transactions on Circuits and Systems - 1, 43, 82-91.

[3] A bu-elma'atti, M. T. and A I-qahatani, M. A. (1998). A new current controlled multiphase sinusoidal oscillator using translinear conveyors. IEEE Transactions on Circuits and Systems - II, 45, 881-885.

[4] A bu-elma' atti, M. T. and A I-qahatani, M. A . (1998). A current mode current controlled current conveyor based analogue multiplier/divider. International J ournal of Electronics, 85, 71- 77.

[5] Kiranon, W., Kesorn, J., Sangpisit, W. and Kamprasert, N. (1997). Electronically tunable multifunctional translinear-C filter and oscillator. Electronics Letters, 33, 573-574.

[6] Khan, I. A. and Maheshwari, S. (2000). Simple first order all-pass section using a single CCII. International Journal of Electronics, 87, 303-307.

[7] Frey, D. R. (1993). Log domain filtering: an approach to current-mode filtering. IEE Proceedings G, Circuit, Devices and Systems, 140, 406-416. 

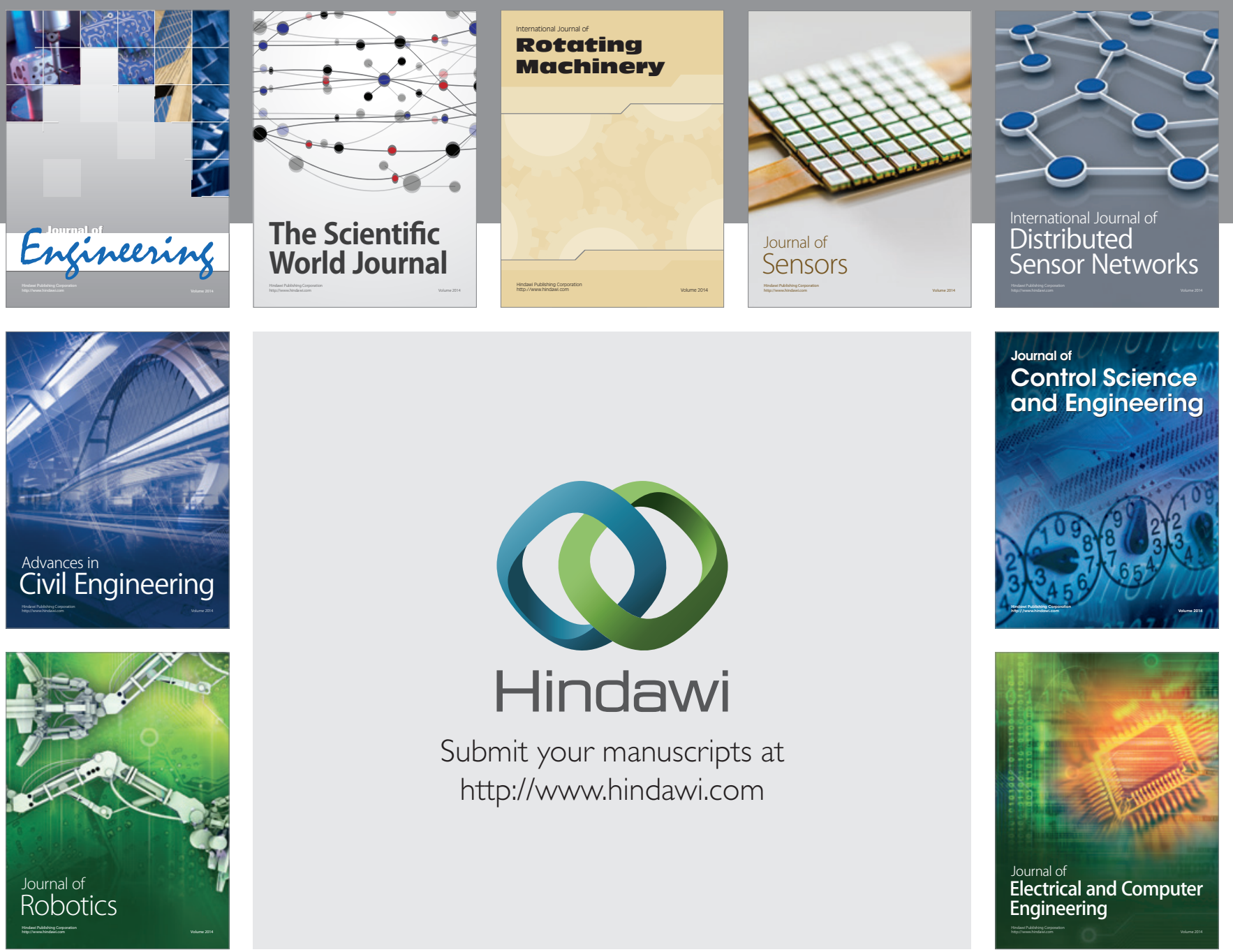

Submit your manuscripts at

http://www.hindawi.com
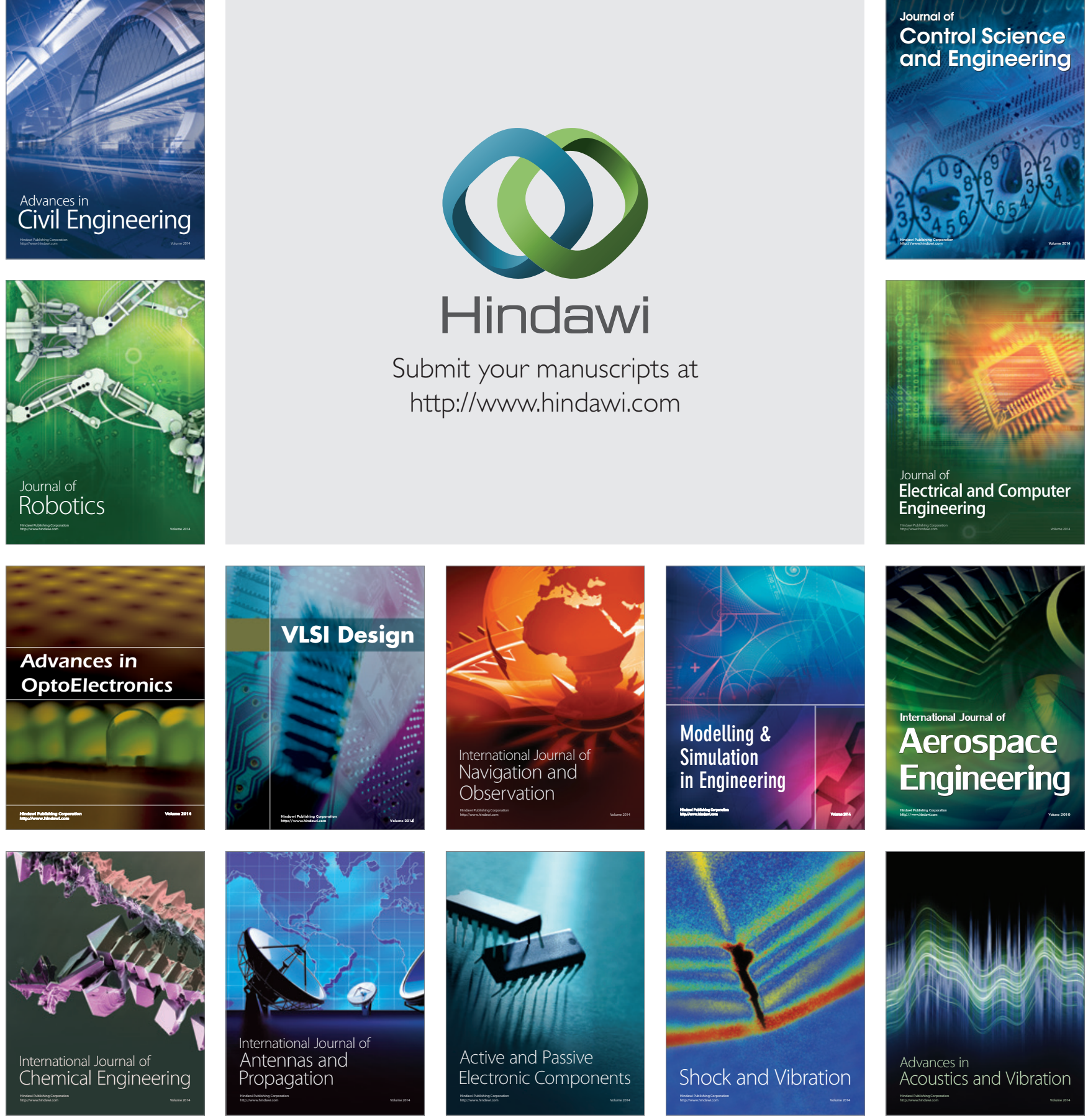